\title{
LA RELIGIÓN COMO IDENTIDAD COLECTIVA: LAS RELACIONES SOCIOLÓGICAS ENTRE RELIGIÓN E IDENTIDAD
}

\section{Religion as a collective identity: sociological relations between religion \\ and identity}

\author{
Alfonso Pérez-Agote* \\ * Catedrático Emérito de Sociología, Universidad Complutense de Madrid \\ aperezag@cps.ucm.es
}

Palabras clave

Religión

Identidad colectiva

Política

Cultura

\section{Keywords}

Religion

Collective identity

Politics

Culture

\section{Resumen}

El presente artículo sociológico trata de establecer la relación entre dos nociones que provienen de ámbitos diferentes: el psicológico y el sociológico. Desde el punto de vista psicológico, se toman como referencia dos niveles de la identidad individual: el personal y el social, aunque éste último se presenta como más relevante para el sociólogo. Desde la llamada sociología histórica el artículo trata de establecer las cambiantes relaciones entre religión, identidad, cultura y política. En primer lugar, durante el periodo histórico de modernización; y, en segundo lugar, en nuestros días, cuando el proceso de globalización difumina los límites precisos de nuestras sociedades.

\section{Abstract}

This sociological article tries to establish the relation between two concepts from different areas: psychological and sociological. From the psychological point of view, two levels of individual identity are taken into consideration: the personal and the social, although the latter is presented as more relevant for the sociologist. From the so-called historical sociology, the article tries to establish the changing relations between religion, identity, culture and politics. First, during the historical period of modernization; and, secondly, in our days, when the process of globalization blurs the precise limits of our societies.

Pérez-Agote, A. (2016). La religión como identidad colectiva: las relaciones sociológicas entre religión e identidad. Papeles del CEIC, vol. 2016/2, papel 155, CEIC (Centro de Estudios sobre la Identidad Colectiva), Universidad del País Vasco, http://dx.doi.org/10.1387/pceic.16178 
1. IDENTIDAD Y RELIGIÓN SON NOCIONES QUE PROVIENEN DE UNIVERSOS TEÓRICOS DIFERENTES, PERO MANTIENEN ENTRE SÍ FUERTES RELACIONES

La dimensión religiosa de la vida social fue un objeto privilegiado del análisis sociológico en sus orígenes ${ }^{1}$. No tenemos más que recordar la producción de los padres fundadores de la sociología ${ }^{2}$. El objeto primero de la sociología fue, históricamente, el proceso de modernización de las sociedades europeas occidentales. Todos los sociólogos atribuyeron a este proceso un carácter secularizador: el proceso de secularización de la vida social era un elemento central de la modernización. Después fue perdiendo importancia la cuestión religiosa para los sociólogos, seguros como estaban de la decadencia de la religión; y, paulatinamente, comenzaron a señalar como excepción el mundo norteamericano. Pero con la llegada a la riqueza económica, o al capitalismo, o a la modernización de sociedades no occidentales -en las que parecía que la religión no presentaba los mismos sintomas de decadencia que en las europeas occidentales - la pregunta sobre el devenir de esta institución social comenzó a ser replanteada. Y, por último, tras las oleadas de inmigración recibidas por las sociedades europeas occidentales después de la Primera y, sobre todo, de la Segunda Guerra Mundial, la pregunta sobre este devenir se extiende al interior de estas sociedades que se pensaban como ya secularizadas; pregunta que se ha ido ampliando hacia nuevos horizontes tras los sucesivos grandes estallidos, surgidos en diferentes partes del mundo, de una violencia definida por sus autores en términos religiosos. La religión, así, en nuestros dias, vuelve a ser un objeto fundamental de reflexión para los sociólogos ${ }^{3}$; además, en los países de Europa occidental, zona desde la que principalmente reflexiono en este trabajo, los flujos de inmigración internacional recibidos desde la primera y, más aún, desde la Segunda Guerra Mundial han producido la quiebra del proceso de progresiva homogeneidad cultural interna de cada sociedad y también el de secularización religiosa de la población.

\footnotetext{
${ }^{1}$ En otras ramas de la ciencia, como la antropología social, también la religión ha sido y es un objeto privilegiado.

${ }^{2} \mathrm{Cfr}$. Hervieu-Léger y Willaime, 2001.

${ }^{3}$ Sobre esta deriva histórica del tratamiento sociológico de la religión, cfr. Pérez-Agote, 2014. En ese trabajo intento establecer los contemporáneos límites de validez científica de la llamada teoría de la secularización para eliminar su dimensión predictiva, profética, y rescatar así su potencial analítico.
} 
Por el otro lado, la cuestión de la identidad ha sido planteada de forma fundamental por la psicología, y, a mi entender, la forma más interesante de hacerlo, pensando en las relaciones entre individuo y sociedad que aquí nos interesan, ha sido la de la llamada psicología social en su vertiente más sociológica, la que intenta no tanto detenerse en la investigación de laboratorio a través de grupos diseñados por el investigador como analizar los procesos sociales concretos que se desarrollan en nuestras sociedades. Desde este último punto de vista, resulta muy útil la representación de la identidad individual a través de lo que ha venido a llamarse los tres niveles del autoconcepto del yo. Según Turner, "al menos hay tres niveles de abstracción de categorización del yo importantes para el autoconcepto social" (1990: 77). El primero está constituido por el nivel superordenado del yo como ser humano y que consiste en determinadas características compartidas con los otros miembros de la especie humana, frente a otras formas de vida. El segundo nivel es el intermedio, compuesto por "las categorizaciones en términos de endogrupo/exogrupo, basadas en semejanzas y diferencias sociales entre seres humanos, que le definen a uno como miembro de determinados grupos y no de otros (por ejemplo 'americano', 'mujer', 'negro', 'estudiante', 'clase trabajadora')" (Ibid.: 77). El tercero sería el nivel subordinado de categorizaciones personales del yo, basadas en diferencias de uno mismo con relación a otros miembros del grupo (Ibid.: 77).

La cuestión religiosa tiene cabida en los tres niveles establecidos por Turner. Es claro que las creencias religiosas $-y$ en general todas las creencias que, como las religiosas, constituyen la plataforma de concepción básica del mundo y de la vida para los individuos- son relevantes a la hora de concebir las relaciones entre los seres humanos y las otras formas de vida, vegetal y animal ${ }^{4}$. Pero es claro que el nivel más relevante para este trabajo es el segundo, el grupal; aunque bien es verdad que el tercero nos plantea a los sociólogos algunos problemas interesantes que aquí no podré sino mencionar.

\footnotetext{
${ }^{4}$ Pero ni siquiera la categoría 'ser humano' es universal. Recordemos, por ejemplo, el caso subrayado por algunos antropólogos sociales de ciertas comunidades en las que la categoría ser humano sólo tiene en su lenguaje la palabra que designa a su propio grupo, sin existir un término genérico que comprenda a su propio grupo junto a los otros grupos humanos.
} 


\section{LA IDENTIDAD COLECTIVA ES UNA CONSTRUCCIÓN SOCIAL}

En relación al segundo nivel del autoconcepto, encontramos la cuestión absolutamente central de lo que los sociólogos llamamos identidades colectivas. Desde el punto de vista psicológico se puede decir que este nivel hace referencia a la conciencia de pertenencia a grupos de cada individuo, la cual forma parte indiscutible de su identidad personal.

Pero, ya desde el punto de vista sociológico, es preciso partir de la afirmación fuerte de que una identidad colectiva no es la mera y directa emanación de un rasgo común. La mera posesión de un rasgo común no determina directamente la aparición de una conciencia de pertenencia común basada en esa posesión. Ningún rasgo produce per se esa conciencia. Para que un rasgo se convierta en un símbolo de pertenencia, es preciso un proceso social que produzca una significación de ese rasgo en términos de identidad colectiva. Es necesario un proceso exitoso: alguien define esa significación, otros la difunden y la significación puede tener éxito o no tenerlo. El éxito máximo se logra cuando el $100 \%$ de los que poseen el rasgo acaban creyendo en la significación difundida y sintiéndose miembros de ese grupo ${ }^{5}$.

Este proceso de atribución y de difusión de una significación es social; en él, no todos los implicados están en la misma posición ni tienen la misma capacidad, el mismo poder. Ello hace que el análisis del sociólogo sea fundamental. Ni siquiera la lengua común, necesaria para que ese proceso - que implica necesariamente comunicación- se lleve a cabo, determina la aparición de una conciencia de pertenencia. Los movimientos de recuperación lingüística aparecen cuando la lengua en cuestión entra en declive, y alguien anuncia - y tiene éxito al hacerloque la lengua está en peligro; e, incluso, el declive puede ser tan fuerte que su anuncio tenga que hacerse en la lengua que se va haciendo dominante y no en la que se quiere salvar. La lengua se hace significante cuando entra en peligro, pero no siempre. En el País Vasco han existido épocas de declive muy amplio de la lengua, en los que éste no ha suscitado un movimiento colectivo general -aunque ciertos sectores ilustrados lo intentaran- de recuperación. La prohibición política del

\footnotetext{
${ }^{5}$ No voy a entrar aquí en las diferentes formas de agrupación humana en función de la predisposición a ser movilizado, la existencia de una conciencia de pertenencia y la interacción continuada. Merton (1980) distingue así entre la mera categoría social (predisposición), la colectividad (conciencia de pertenencia) y el grupo (conciencia con interacción).
} 
uso público de esta lengua por el régimen franquista, sin embargo, produjo, como he mostrado en mis investigaciones ${ }^{6}$, un movimiento imparable de recuperación. No es el declive lo que produce la conciencia, sino un proceso social que logra éxito.

La conciencia de pertenencia es compartida con otros; y ello implica que esta conciencia haya sido producida y mantenida, necesariamente, mediante mecanismos sociales. Con respecto al horizonte semántico de la Psicología, el sociólogo no puede suponer, analógicamente, que la sociedad o un grupo social tienen una conciencia, sienten como un individuo. La identidad colectiva no es la transposición al grupo de la conciencia de identidad personal. Las identidades colectivas son realidades socialmente producidas, socialmente objetivadas que, además, a través de los procesos de socialización y de interacción en general se convierten en elementos de la identidad personal.

La conciencia individual de identidad colectiva y la representación social de esa identidad no son emanación de la realidad material, sino que son realidades simbólicas socialmente construidas en un mundo social compuesto de sujetos desiguales en términos de capacidad para producir y difundir representaciones que llegan a ser abrazadas por un conjunto de individuos que, al abrazarlas, se constituyen en un grupo, con un sentido de pertenencia mutua. Esto hace que la identidad colectiva sea objeto de análisis sociológico.

Tajfel enumera los componentes que, con mayor o menor intensidad, constituyen lo que es un grupo de pertenencia:

"Componente cognitivo, en el sentido del conocimiento de que uno pertenece a un grupo; componente evaluativo, en el sentido de que la noción de grupo y/o de la pertenencia de uno a él puede tener una connotación valorativa positiva o negativa; y componente emocional, en el sentido de que los aspectos cognitivo y evaluativo del grupo y de la propia pertenencia a él pueden ir acompañados de emociones (tales como amor u odio, agrado o desagrado) hacia el propio grupo o hacia grupos que mantienen relaciones con él" (1984: 264).

\footnotetext{
${ }^{6}$ En mi obra más desarrollada sobre la cuestión vasca (Pérez-Agote, 2006 y 2008) puede verse como el nacimiento de ETA está directamente vinculado a la toma de conciencia de esta prohibición política; posteriormente, nacería un movimiento clandestino de recuperación lingüística.
} 
Los sociólogos decimos que las identidades colectivas son realidades sociales y hacemos de ellas un objeto de nuestro análisis. Las identidades colectivas pertenecen primordialmente al mundo de las representaciones e imágenes de la realidad $y$, en su proyección individual, al mundo de la conciencia. Representación y conciencia que, al ser observadas por el sociólogo, deben ser tomadas como tales, en tanto que fenómenos sociales, en el sentido husserliano de este término; pero apartándonos de la conexión husserliana entre representación del objeto y el objeto de la representación; el sociólogo no debe enjuiciar la validez científica de la representación; la representación es la realidad para él, independientemente de que sea veraz; es real porque existe y determina el comportamiento de quien la tiene, no porque sea verdadera; lo cual implica, a su vez, que representación y conciencia pueden ser esencialistas $y$, de hecho, suelen serlo. Estamos dentro del mundo de las creencias. El sociólogo debe analizar cómo se producen y se reproducen y cómo determinan el comportamiento de los individuos.

Una identidad colectiva lleva implícita, siempre, una definición social de una realidad colectiva. Esta definición no es real porque sea verdadera como tal definición. El componente cognitivo de un grupo es real independientemente de que sea verdadero desde un punto de vista científico. La definición es real porque existe, y existe mientras sigue siendo mantenida por los miembros y determinando su comportamiento.

En este segundo nivel de los señalados por Turner, el de la identidad colectiva, encontramos que el individuo se ve a sí mismo como siendo una serie de atributos. Estos atributos - con una dimensión cognitiva que le dice al individuo lo que es-son materia socialmente construida y aprehendida por el individuo en sus interacciones con otros. Todos los atributos son atributos sociales, en el sentido de que su significación es socialmente construida. Incluso los atributos que tienen una base puramente biológica, como puede ser el color de la piel, son en realidad sociales. Ser negro no es importante en sí; su significación depende del contexto social en el que el individuo vive. Ser negro puede ser insignificante en una comunidad del África subsahariana y puede ser muy significante en una ciudad de habitantes mayoritariamente blancos. El color de la piel no es el atributo; el atributo está constituido por el citado color en una relación de significación social. Los atributos 
de los grupos, por ello, son símbolos y, por lo tanto, son siempre sociales. La significación social de un rasgo, no es una emanación directa del rasgo mismo, sino que es una construcción social, es el resultado de un proceso social en el que no todos los actores sociales están en la misma posición social a la hora de generar la significación, de difundirla y de alcanzar éxito en la difusión. Por ello es necesario el análisis sociológico de este nivel de la identidad.

De la necesidad de contemplar las representaciones sociales de realidades colectivas, que viven en las conciencias de los individuos, y los procesos sociales de construcción y difusión de estas representaciones, surge la necesidad de observar dos momentos metodológicos (PérezAgote, 1995) para el análisis de la identidad colectiva. En el momento fenomenológico se constituye la representación y la conciencia en objeto, evitando así todo juicio sobre la veracidad o cientificidad de éstas. En el momento genético la mirada se dirige a la producción de la representación, a los mecanismos de difusión social y al proceso performativo por el cual las definiciones sociales de realidades colectivas tienen un cierto éxito, que implica que generan la realidad que definen: el grupo de pertenencia.

\section{LA RELIGIÓN PUEDE SER LA DIMENSIÓN LÍMITE, TOTALIZADORA DE LA IDENTIDAD COLECTIVA}

Al examinar el repertorio de identidades colectivas mantenidas por los individuos, podemos ver que existe un tope, un límite para la pertenencia, más allá del cual el mundo social existente no es considerado como propio. Aunque esta identidad colectiva límite no tenga una expresión sensible en ciertos momentos, alcanzará su significación cuando el conjunto de individuos que se incluye dentro de él entra en relación de proximidad con individuos o grupos exteriores a ese límite. El conjunto de individuos que está dentro entra en relación de alteridad con los de fuera, con lo cual la identidad colectiva de los de dentro cobra sentido; sentido inexistente sin esa alteridad.

La posible pertenencia de un individuo a otro agregado social del mismo -el más alto- nivel de amplitud y generalidad, le plantea problemas difíciles de compatibilidad, en varios horizontes, como el afectivo e, incluso, el jurídico. Ello no quiere decir que no se den casos de doble 
pertenencia, sino que la doble pertenencia puede llevar consigo problemas, tanto de índole personal como social y política.

Para Durkheim, en la religión se encuentra la forma primera de ese espíritu común que hace que la sociedad se mantenga unida en su conjunto. La sociedad es "un conjunto de ideas, de creencias, de sentimientos de todos los tipos que se desarrollan por los individuos" (Durkheim, 1967: 79). Para este autor, "estudiar la religión es, por tanto, remontar a las fuentes del vínculo social para poder pensar mejor la refundación posible de este vínculo en una sociedad que ha llegado a ser laica" (Hervieu-Léger y Willaime, 2001: 155). En su gran obra sobre la religión, Les formes élémentaires de la vie religieuse, publicada en 1912, Durkheim (2007) estudia las religiones totémicas australianas, pero su preocupación iba más lejos, pues quería saber cómo construir esa unidad moral en una sociedad laica, la francesa, que acababa de promulgar la ley de 1905 que institucionalizaba definitivamente la separación entre la Iglesia y el Estado. Por ello en esa obra hablaba con frecuencia de esa nueva unidad moral que era la Nación.

Dónde se sitúa el límite más amplio de la pertenencia de un individuo ha ido variando, y en general, ampliándose a lo largo de la historia. Podemos pensar en la comunidad local en la época premoderna, en la comunidad nacional en la época moderna y en la ruptura de estos límites en la contemporánea globalización.

La modernidad supuso, como ya nos advirtió Thomas en 1923, un debilitamiento profundo de la comunidad local como agencia definidora de la situación:

\begin{abstract}
"Ahora la comunidad es tan débil y vaga que no nos da una idea del antiguo poder del grupo local en la regulación del comportamiento. Originalmente la comunidad era prácticamente todo el mundo de sus miembros. Estaba compuesta por familias relacionadas por la sangre o por matrimonio y no era tan grande que no pudieran reunirse todos sus miembros; era un grupo de relaciones cara a cara. Pregunté a un campesino polaco cuál era la extensión de una akolica o vecindad, hasta dónde llegaba. 'Llega', dijo, 'hasta donde llega la noticia de un hombre, hasta donde se habla de uno'" (1923: 43).
\end{abstract}

La sociedad polaca que veía Thomas era una realidad social cerrada en la que, desde el punto de vista de la identidad, el límite para el individuo estaba en su comunidad local. Todo lo que pasaba en ella le afectaba, y 
todo lo que le afectaba, pasaba en ella. Con la emigración polaca a los Estados Unidos, esta simetría casi perfecta para el individuo se rompió y la realidad social dejó de ser cerrada. En relación al cotilleo, dice Thomas que "fue significativa la afirmación del campesino polaco de que 'la comunidad se extiende hasta donde un hombre anda en boca de todos', ya que en gran parte la comunidad regula la conducta de sus miembros hablando sobre ellos" (Thomas y Znaniecki, 1958: 57).

La Reforma dividió el paisaje religioso europeo. Y, con ello, disminuyó el poder de la Iglesia católica para castigar, a través del poder del Estado, a quienes se desviaban de la religión verdadera. Tras la Reforma viene una época de fuertes guerras religiosas entre príncipes: entre católicos, calvinistas y luteranos. La paz de Westfalia (1648) fue un acontecimiento muy relevante para hacer del Estado el locus fundamental del control religioso. La fórmula cuius regio eius religio, que se adoptó en ella, significaba que la religión del príncipe se constituía en la del pueblo que habitaba el territorio. La identificación entre comunidad religiosa y comunidad política se plantea como una necesidad: la uniformidad de una norma moral para todos los miembros del Estado. El Estado necesitaba la argamasa, el cemento religioso que unificaba a los súbditos en una única comunidad. La pretensión era que la comunidad política fuera la comunidad religiosa. Tras ello, el proceso de modernización vendría a independizar al Estado - al poder político-de la religión y de la Iglesia, a través de la idea de nación: una comunidad civil de la que emanaba la autoridad política. El poder ya no venía de Dios.

El proceso de construcción de cada Estado europeo llevó consigo una descentración de las decisiones que afectan al individuo y una nueva centralidad fue apareciendo en la vida de éste, la del Estado; la sociedad local seguía significando para el individuo un lugar donde todo lo que pasa le afecta pero ya no era el lugar donde pasa todo lo que le afecta, pues hay cosas que le afectan que vienen de lejos, del centro del Estado, que muchas veces ni siquiera ha visitado. En este sentido la modernización es un proceso de ruptura de la ecuación conocimientoafectos, pues la sociedad local comienza a estar exo-centrada. Sin embargo, el nacionalismo, como vehículo de difusión de la idea y el sentimiento nacionales, restituirá progresivamente la cohesión emocional del grupo, reconstituyendo así la ecuación a una escala mayor. Dice Kohn que "el individuo del nacionalismo tenía sus raíces en 
el orden de las emociones de grupo y en la cohesión 'natural'"(Kohn, 1949: 168-169).

En la modernidad de los países occidentales la nación ha constituido este agregado límite para el individuo, en términos de generalidad y de compatibilidad. En otras latitudes y en otros tiempos, otras formas de identidades colectivas han significado ese microcosmos simbólico general y completo que pone límites a la significatividad simbólica y que, por tanto, pone trabas y límites a la doble pertenencia.

\begin{abstract}
"La identidad menos especializada, aquella de más amplia circunferencia, que se presume define la profunda esencia de la persona y guía sus acciones en muchas esferas de la existencia social es, por supuesto, la más poderosa. La imagen del orden social está reflejada en ella en forma poderosa; representa dicha imagen en un microcosmos. En el curso de la historia la esencia del pueblo ha sido definida por diferentes identidades. En numerosas sociedades la identidad religiosa llevó a cabo esta función. En muchas otras el estamento o la casta hicieron lo mismo. Esa identidad generalizada en el mundo moderno es la identidad nacional" (Greenfeld, 1992: 20).
\end{abstract}

Lo que se rompe en nuestras sociedades europeas occidentales con la globalización es algo que primero se había perdido con la construcción del Estado y después se había recuperado con el nacionalismo y el establecimiento de las democracias nacionales: un equilibrio, al menos relativo, entre lo que el individuo conoce y lo que le afecta, entre conocimiento y afectos; ello implica un límite dentro del cual pasa todo lo que le afecta y, también, todo lo que pasa le afecta: el límite geográfico, social y político de la nación y el Estado. Con la globalización el difícil equilibrio conseguido en la modernización se comienza a resquebrajar. Agentes políticos y económicos supranacionales organizaciones políticas supraestatales, corporaciones multinacionales, instituciones del capital financiero- toman decisiones que afectan directamente al individuo en aspectos centrales en su vida. Este individuo desconoce en gran parte lo que le afecta, ya que gran parte de las decisiones que le afectan directamente se producen en ámbitos que él desconoce. Sin embargo, por la globalización cultural -medios de comunicación, internet-alcanza a conocer ámbitos del mundo que no le afectan en su vida: puede ver en la televisión cómo mueren de hambre niños de un país lejano mientras trata de digerir la decisión tomada por los dirigentes - que no sabe quiénes son y que se han reunido en algún 
lugar que desconoce- de una sociedad multinacional, por la cual la factoría en la que él mismo trabaja va a desaparecer. El equilibrio entre conocimiento y afectos está, al menos por el momento, roto?

En nuestra época pueden producirse también combinaciones complejas entre los límites religiosos y políticos de la identidad, como podemos observar en los conflictos políticos en el Este de Europa tras la caída del Telón de Acero (1989); la pérdida de protección política de la ideología oficial soviética supuso una re-etnización de la identidad política, lo que implicaba con cierta frecuencia que una determinada confesión religiosa fuera un elemento central de la identidad política propugnada.

En general, se puede decir que la identidad colectiva religiosa se manifiesta en forma activa también en aquellas realidades sociales en las que conviven diferentes confesiones religiosas. La diversidad religiosa presente en una sociedad puede dar lugar a diferentes formas de convivencia. Una factor fundamental que define la forma de la coexistencia es la posible jerarquización social de las diferentes confesiones; es el caso de los países en los que una determinada confesión es la confesión que ha sido históricamente la de referencia y a los que, con posterioridad a esa homogeneidad, van llegando flujos de población extranjera portadora de creencias religiosas diferentes ${ }^{8}$. Este es el caso de las sociedades europeas occidentales en la época contemporánea, en la que las dos leyes enunciadas por Tilly para la modernización de estas sociedades comienzan a difuminarse.

\section{LA GLOBALIZACIÓN DIFUMINA EN EUROPA OCCIDENTAL LOS PROCESOS CULTURALES DE LA MODENIZACIÓN: LA CRISIS DE LAS DOS LEYES DE TILLY}

La sociología histórica ha sido esencial para comprender el proceso por el cual se van formando en Europa los Estados. Para el "sistema europeo de Estados", establecido con la Paz de Westfalia, Tilly (1990) describe dos leyes que definen el proceso histórico posterior: la de la progresiva

\footnotetext{
${ }^{7}$ Este desequilibrio constituiría posiblemente una forma de anomía. Por otro lado, la navegación por internet abre nuevas posibilidades de relación entre conocimiento y afectos desligadas del territorio.

${ }^{8}$ Un caso interesante, aunque fuera del objetivo de este trabajo, es el de la adscripción de un status social a cada confesión religiosa en Estados Unidos; de manera tal que un individuo que asciende claramente de nivel profesional y social puede verse compelido a cambiar de confesión religiosa, para adoptar la que socialmente corresponde a su nueva situación (Berger, 1967).
} 
homogeneización cultural interna de cada Estado y la de la también progresiva heterogeneización entre todos ellos. Quedémonos ahora en la primera. Para darse cuenta de la consistencia de este proceso de homogeneización cultural de la población podemos pensar en el modelo general de formación de estos Estados ${ }^{9}$. Su centro político-territorial se definió en un largo proceso histórico, a través de guerras, tratados de paz y matrimonios reales. Dentro de estos territorios que se fueron anexionando habitaban poblaciones con culturas, con lenguas y con religiones distintas. A partir de ciertos momentos, los Estados comenzaron con una política homogeneización cultural de estos grupos étnicos preexistentes. Esta homogeneización nunca ha llegado a ser total, pero sobre esas formas diferentes se fue asentando una lengua y una cultura nacionales, e, incluso, una sola confesión religiosa se fue universalizando en cada pais ${ }^{10}$. En este caso, el más general en Europa occidental, el Estado fue previo a la existencia de una homogeneidad cultural interna y de una comunidad nacional; una tarea básica de ese Estado fue la homogeneización cultural de todos los diferentes grupos étnicos que vivían dentro del territorio estatal: "la nación es hija del Estado" (Nisbet, 1973: 164). El sistema público de educación, la red de comunicaciones, el servicio militar obligatorio, fueron, entre otros, mecanismos importantes de extensión de una cultura y una lengua nacionales. (Pérez-Agote, 2006: cap. 2). En el proceso de democratización-nacionalización del Estado, fue necesaria la idea de nación: la nueva identidad colectiva en la que reside el poder, en sustitución de la idea del derecho divino de los reyes. Es en este proceso cuando el Estado debe autonomizarse de la religión y de la Iglesia dominantes. La idea de nación fue una idea secularizadora en el campo de la legitimación política.

Las dos leyes establecidas por Tilly para definir la transformación de las sociedades europeas desde la Paz de Westfalia hasta finales del siglo XX se han visto profundamente perturbadas durante las últimas décadas, a causa del llamado proceso de globalización.

Por un lado, la heterogeneidad entre los Estados se ve afectada por la progresiva homogeneización cultural que la globalización conlleva. Pero, por el otro lado, la globalización no sólo homogeneiza, sino que, a través

\footnotetext{
${ }^{9}$ Para tener en cuenta la relativa diversidad de modelos, cfr. Pérez-Agote, 2006.

${ }^{10}$ Pensemos, por ejemplo, en el principio cuius regio eius religio, al que ya he hecho referencia, como forma de homogeneización interna de la población.
} 
de las nuevas migraciones internacionales también produce una heterogeneización interna de las sociedades occidentales. La globalización produce dos lógicas culturales contradictorias: la "mcdonaldizacion" de la sociedad (Ritzer, 1996) coexiste y compite con la "re-creación ${ }^{11}$ cultural" (Wieviorka, 1998) de las poblaciones inmigradas. La occidentalización o la americanización generalizada de la cultura es un fenómeno bien interesante y con consecuencias muy relevantes por acción y por reacción- en el campo religioso; pero desde el punto de vista de las relaciones entre las nociones de religión e identidad, es el otro aspecto, el de la recreación cultural llevada a cabo por las poblaciones inmigradas, en situación de minorización social, el que tiene una importancia extraordinaria.

El proceso de globalización, lejos de resolver las grandes diferencias ocasionadas por la división internacional del trabajo entre el Norte y el Sur, ha intensificado de manera importante las migraciones internacionales. Un factor importante ha sido, sin duda, el hecho de que las nuevas tecnologías de la comunicación y la difusión a escala mundial de la televisión han ido globalizando una imagen de las formas de vida occidentales.

Los flujos de población inmigrante comienzan a llegar a los países más ricos de Europa occidental tras la Primera y, sobre todo, tras la Segunda Guerra Mundial. Es un proceso masivo que primeramente se produce desde países europeos pobres o superpoblados hacia los países más ricos del continente. Poco después comenzará la inmigración a las metrópolis de población de las viejas colonias. En esa época los países europeos industrializados necesitaban mano de obra, por lo que la adaptación de esta población inmigrante a esta nueva situación fue relativamente fácil desde un punto de vista económico, laboral, dada, por una parte, la necesidad objetiva de mano de obra y, por la otra, la actitud instrumental propia del emigrante, que viaja dispuesto a resolver pragmáticamente un problema (suyo, de su familia o, incluso, de su pequeña comunidad local) mediante el sacrificio personal de abandonar voluntariamente la sociedad propia. Durante mucho tiempo, la situación social de la población inmigrada no se plantea como problemática en Europa; los graves problemas comienzan a partir de la crisis del petróleo

\footnotetext{
${ }^{11}$ En Kivisto (2014: 61-87) podemos ver las formas de re-creación de la organización eclesial por la población inmigrante, muchas veces muy cercanas a las formas de organización de las confesiones autóctonas.
} 
de los 1970s, con las perturbaciones que ocasiona en el mercado laboral. Los requisitos político-administrativos para la inmigración se fueron dificultando; en los 80s, las diversas administraciones europeas intentaron limitar nuevos flujos de inmigración, permitiendo solamente los casos de "reagrupación familiar". En esos mismos años ochenta, la primera generación inmigrante había ya obtenido la residencia permanente, pero la segunda generación salía del sistema educativo del país receptor y su inserción laboral era muy problemática dada la crisis económica; comenzaron los grandes conflictos urbanos de barrios con alto componente de población inmigrada (Lapeyronnie, 1987). En los años 90, la caída del Telón de Acero, abrió otro flujo fuerte de migración desde el Este al Oeste de Europa. Y ya con el comienzo del siglo actual, algunos países que, como España, habian sido tradicionalmente emigrantes hasta los años 70, comienzan a recibir grandísimos contingentes de población de África, de América Latina y, algo después, de Europa del Este.

En el siglo $X X$, desde el fin de la Primera Guerra Mundial, ha sido muy cambiante el nivel de la homogeneidad cultural y religiosa de las sociedades europeas. El ritmo de cambio se incrementó después de la Segunda y todavía más aún en el último cuarto del siglo. Los intentos de homogeneización absoluta o relativa, según los modelos políticos desarrollados por los distintos países, de la población inmigrante han sido un fracaso importante, como se empezó a poner de relieve a finales de la década de 1970 y, sobre todo, en los ochenta, tras la crisis del petróleo, cuando la segunda generación de la población de origen inmigrante, tras haber pasado por el sistema educativo nacional, intenta incorporarse al mercado de trabajo y encuentra dificultades que en muchos casos llegan a la exclusión. Los conflictos sociales de la joven generación de origen inmigrante no tardaron en comenzar a producirse.

A partir de la crisis de los años 70 comienza a darse un contraste entre la debilidad de los mercados europeos de trabajo y las progresivas dificultades impuestas por Europa a la entrada de inmigrantes, por un lado, y, por el otro, el mantenimiento de las condiciones estructurales de los países con tendencia a emigrar y con las redes sociales en gran parte establecidas para hacerlo. Este contraste ha venido produciendo tres consecuencias fundamentales en el terreno de las migraciones internacionales. La primera está constituida por el crecimiento de los riesgos vitales asumidos por las poblaciones que continúan intentando 
emigrar; la segunda por el crecimiento de la inmigración ilegal en los países receptores; y la tercera gran consecuencia se da en el campo de las segundas generaciones de las poblaciones inmigradas ya establecidas en los países europeos: muchos descendientes de inmigrantes llegados en una época en la que el mercado de trabajo tenía necesidad de ellos, se confrontan a una situación diferente de la de sus padres en relación a los principales mecanismos de integración de la sociedad.

Como mecanismos públicos de integración para la población en general están el sistema educativo $y$, en relación muy estrecha con él, el mercado de trabajo. No se puede generalizar mucho sobre la situación del sistema de enseñanza en los diferentes Estados europeos, pero, en todo caso, si la salud del mercado de trabajo no es muy buena estas segundas generaciones de origen inmigrante han tenido y tienen problemas para integrarse en la sociedad, para llegar a adquirir una identidad social y para dotarse de una autoestima positiva a través del trabajo y la profesión. Por otra parte, el mecanismo social privado por excelencia, la familia, se encuentra también en una situación problemática. Los padres, inmigrantes en una época en que los factores de atracción estaban presentes, han tenido un comportamiento instrumental adaptativo, y, por ello, elaboraron una estrategia adaptativa para la educación de sus hijos. La deterioración de los mecanismos públicos de integración provoca algunos efectos: la aparición de conflictos entre los jóvenes y la sociedad receptora; la búsqueda de una identidad social y de nuevas fuentes de autoestima y de estima social, dadas sus dificultades para entrar en el mercado de trabajo; la revalorización, por consiguiente, de la cultura y de la lengua originales. Este último efecto puede, a su vez, producir otro: puede hacer ambivalentes las relaciones intergeneracionales intrafamiliares. Sus padres habian dado prioridad a la lengua y a la cultura de la sociedad receptora y ellos vuelven su mirada hacia la sociedad originaria. La relación entre ellos se hace ambivalente, porque, por un lado, están contra sus padres porque relegaron la lengua, la cultura y la religión originarias. Pero, por el otro, están a favor de ellos debido al afecto y a que sus padres representan y mantienen, precisamente, la lengua, la cultura y la religión originarias.

Las dificultades de inserción laboral de los jóvenes de origen inmigrante provocan conflictos entre ellos y la sociedad de acogida; por ello, estos 
jóvenes buscan encontrar otra identidad social, otras fuentes de autoestima y de estima social, como pueden ser la cultura, la religión y la lengua originarias de esa población. La religión se convierte, para los que intentan recuperarla, en una religión por opción más que por herencia, pero carente ya para ellos de la envoltura de la cultura originaria, pues su vida en el barrio y en el centro educativo la desarrollan en un medio cultural diferente al medio cultural originario de sus padres.

Para los inmigrantes en general, la religión ofrece un valor añadido social en términos de refugio social y de fuente de identidad, de autoestima y de solidaridad pragmática ${ }^{12}$. Cuanto menos funcionen en esa población los mecanismos sociales públicos de integración (sistema educativo, mercado de trabajo y adecuación entre ambos) mayor se vuelve la necesidad para esta población de lograr la estima social y la autoestima a través de recursos propios. Como nos recuerda Roy (2005), el Islam es, también, una religión europea. Lo cual, a su vez, nos plantea el problema evocado por el propio Roy: la vuelta de los jóvenes en Francia a una religión islámica de opción (Tietze, 2002), tras haber sido previamente des-arabizados y des-islamizados por la escuela republicana y de no haber sido con posterioridad aceptados por el mercado de trabajo, es la vuelta a una religión desprovista de la envoltura cultural general que tiene en el caso de sus antecesores; esta religión des-culturizada es más proclive a la letra que al espiritu, y más proclive, por tanto, a derivar en proposiciones fundamentalistas ${ }^{13}$ (Khosrokhavar, 1994: 130-131). Se trataría así de un proceso drástico, dramático y traumático de diferenciación funcional, de separación entre la religión y la cultura islámicas ${ }^{14}$.

“No hay (en Francia) tercera, cuarta o enésima generación de yihadistas. Desde 1996, estamos confrontados a un fenómeno muy estable: la radicalización de dos categorías de jóvenes franceses, a saber, musulmanes de 'segunda generación' y convertidos de origen autóctono" (Roy, 2015).

\footnotetext{
${ }^{12}$ En Adogame (2014) podemos encontrar la gran variedad de funciones que puede cumplir la religión en caso de minorización social. Este libro contiene estudios monográficos sobre nuevos movimientos religiosos de origen africano en varios países, la mayoría europeos.

${ }^{13}$ Pero es preciso tener en cuenta que esta deriva no es universal. En un trabajo reciente se muestra cómo jóvenes de origen argelino de los llamados barrios sensibles acceden en la región de París, île de France, al trabajo y a la profesionalización (Boucenna, 2016).

${ }^{14}$ En nuestros días ya está entrando en la arena pública la tercera generación, y continúan las dificultades de entrada en el mercado de trabajo.
} 
"Sí y no". Gran parte de los musulmanes, especialmente los ancianos, está en una lógica de secularización total. Sin embargo, la generación más joven está mucho más en una forma de reivindicación de lugar en la sociedad y de crítica del orden social. Las ideologias de izquierda, comunista, etc. desaparecieron. Por lo tanto algunos jóvenes utilizan el vocabulario político del Islam para diferenciarse, lo que explica, por otra parte, a causa del vacío del resto, el número de conversiones, que ahora alcanza su punto máximo. Este es un fenómeno sorprendente entre los que parten a la yihad en Siria, donde el número de conversos alcanza el 25 o 30\%. Esto pone de manifiesto que una ideología radical, cualquiera que sea hoy en día, y aquí es el vocabulario del Islam, es capaz de penetrar más allá de los círculos tradicionalmente musulmanes" (Kepel, 2015: 97).

En los textos de Roy y de Kepel ${ }^{16}$, dentro de sendos recuadros, podemos ver una coincidencia de estos dos excelentes analistas del devenir del islam francés, en relación al fenómeno de la radicalización juvenil de corte islamista ${ }^{17}$. En ella se daría una convergencia de jóvenes de origen inmigrante radicalizados tras el proceso de exclusión en el mercado de trabajo con jóvenes de origen francés radicalizados, que, desencantados del lenguaje tradicional izquierdista de protesta, adoptan el nuevo lenguaje de radicalización islamista. Pero parece ser, siguiendo esta visión hipotética, que la relación de unos y otros jóvenes con la religión musulmana y con las formas culturales de la generación, tiene rasgos de nuevo cuño que la investigación social tendrá que descifrar ${ }^{18}$. Por un lado tenemos la fórmula empleada por Roy para hablar de los jóvenes de origen francés: son radicales que se islamizan, que se convierten al islam, que lo adoptan para expresar su radicalidad. Por el otro, están esos jóvenes de origen inmigrante que optan por el islam, como religión de opción, dado el proceso de exclusión social sufrido; es la religión de

\footnotetext{
${ }^{15}$ Se trata de una respuesta de Gilles Kepel en una entrevista a esta pregunta: “¿Diría que el Islam en Francia está en vías de secularización?".

${ }^{16}$ Dejo fuera la cuestión de hasta qué punto ocurre la secularización de los musulmanes de la primera generación, cuestión de difícil respuesta, dados los déficits de información etno-religiosa de las estadísticas francesas.

${ }^{17}$ Recordemos los dos grandes atentados de este tipo ocurridos en París en 2015: el de Charlie Hebdo, el 7 de enero, y el del teatro Bataclan el 13 de noviembre.

${ }^{18}$ Un tema central será, sin duda, el de las características de esa religión, de opción en ambos casos.
} 
sus padres, pero sin su correspondiente envoltorio cultural. y todo ello parece conformar un entramado cultural y religioso complejo, al que la ciencia social deberá dedicar buena atención.

Volviendo a las leyes de Tilly, podemos decir que la tendencia a la heterogeneidad entre los Estados se ve afectada por la progresiva homogeneización cultural que la globalización conlleva. Pero, por otro lado, la globalización no sólo homogeneiza, sino que, a través de las nuevas migraciones internacionales, también produce cierta heterogeneidad interna de las sociedades occidentales, desde el punto de vista religioso y cultural, y, además, desde el punto de vista de las relaciones entre la religión y la cultura, como veremos. La globalización produce, así, dos lógicas culturales contradictorias que compiten entre sí y, además, debilitan la cultura nacional relativamente homogénea a la que se refería Tilly.

\section{LAS DIFERENCIAS DE LA MODERNIDAD (RELIGIÓN, POLÍTICA, CULTURA) Y SU CRISIS}

La separación, moderna, entre el Estado como institución y la Iglesia predominante en el territorio de ese Estado fue llevada a cabo en los diferentes países a través de estrategias distintas, resultando formas bien diversas de diferenciación ${ }^{19}$. Pensemos en Francia, Inglaterra, España... Modelos distintos, velocidades diferentes, radicalidad absoluta de la lucha entre instituciones o totalmente inexistente; pero conduciendo siempre a la secularización de la legitimación del poder político: en la modernidad, el poder reside en la comunidad nacional.

El proceso de separación entre Iglesia y Estado fue un proceso difícil y largo, y más dramático aún en los países católicos. Esto último se debe se debe a que donde triunfó la Reforma protestante, la Iglesia comenzó a tener un control directo menor sobre la vida social. Por la desaparición

\footnotetext{
${ }^{19}$ Este trabajo está referido a los países de Europa occidental. Pero un caso bien interesante es el de Estados Unidos, en donde la religión adquiere un peso muy grande en el proceso, y, sin embargo, la separación entre la Iglesia y el Estado es absoluta: la primera enmienda de la Constitución americana impide la financiación pública de las Iglesias; éstas son muy importantes en la vida social, pero deben ser financiadas por sus propios "clientes"; pero la importancia pública de la religión es tal que se construye una metareligión política, que no puede hacer referencia sino a un Dios genérico, sin especificación alguna que se refiera a una confesión concreta; pensemos en expresiones de la vida política tales como God bless America! o en la que preside el billete de un dólar: In God we trust.
} 
de los sacramentos, que ritualizan los momentos claves del ciclo vital, y, sobre todo, por la extensión de la idea del libre examen, que quiebra el papel de esa institución como administradora de la verdad: Dios habla directamente a los hombres. Todas estas características de la Reforma tuvieron un papel importante en el libre desarrollo de la ciencia y también significaron una pérdida de poder social y político para las Iglesias reformadas, en comparación con el que mantenía la Iglesia católica en los países en que ésta era la religión dominante.

Por otra parte, durante el proceso de construcción/democratización/nacionalización de los Estados europeos occidentales, ocurre otro proceso de diferenciación que es menos aparatoso y menos visiblemente trascendente desde el punto de vista político. Es el proceso de diferenciación entre religión y cultura. En el mundo premoderno, ambas instituciones no estaban, al menos claramente, diferenciadas.

El mundo de los significados compartidos, la cultura, está objetivado por la mera intersubjetividad. Al menos hasta que emerge una objetivación, una institucionalización de ese mundo, una autoridad diferenciada que interpreta la tradición, el saber. Tanto más cuando el saber está escrito. En las sociedades antiguas, la emergencia de la escritura probablemente determina que el conocimiento de la comunicación escrita -escribir y leer- sea el anclaje social primario de la emergencia de esta autoridad. La institucionalización máxima de la religión surge con el libro, con la religión de libro. Con anterioridad, claramente existe la autoridad, pero ésta no es específicamente religiosa, sino la autoridad simbólica general que incluye las formas que luego se escindirán dentro del mundo simbólico: la cultura y la religión. Dentro de este mundo simbólico, es la religión la que se diferencia, la que se separa.

Luego se separarán otros semi-conjuntos de significados, en particular, la ciencia, controlada por otro grupo social diferenciado y jerarquizado internamente también. El resto indiferenciado, como código de significación y como grupo que jerarquizadamente lo controla, se seguirá manteniendo por uso en la intersubjetividad más o menos general. De manera que, desde este punto de vista, la cultura puede entenderse como la parte menos institucionalizada del mundo simbólico, aquella en la que no existe una autoridad claramente diferenciada y se rige por los mecanismos sociales generales que, desde luego, están - más o menos sutilmente- jerarquizados. En un reciente 
coloquio del Groupe Sociétés, Religions, Lä̈cités ${ }^{20}$-al que tengo el gusto de pertenecer- Jean Baubérot expresó esta idea de forma contundente: "Ia religión es la parte más institucionalizada de la cultura".

La diferenciación de la cultura y la religión fue un proceso lento, complicado y menos visible y relevante desde el punto de vista político que el de separación entre la Iglesia y el Estado. Porque no se trataba tanto de una diferenciación entre instituciones sino, más bien, de una diferenciación de esferas: entre una esfera simbólica profundamente institucionalizada en los países occidentales, la esfera religiosa, y otra esfera, la de la cultura, que estaba y está muy débilmente institucionalizada. Cuando la cultura se va desprendiendo, independizando, de la religión, no se genera una institución específica para su mantenimiento y su control. No puedo entrar aquí en la cuestión de establecer qué es la cultura, sin duda uno de los términos más discutidos por las ciencias sociales. Utilizando el término en un sentido plano, como significados compartidos por una población, lo que quiero señalar es que no existe una única y diferenciada institución de control general de la cultura, que señale lo que es la ortodoxia y que sancione la heterodoxia negativamente (como hace la Iglesia en el campo religioso) o positivamente (como a veces, no siempre, ocurre en el campo de la ciencia). La cultura en general se mantiene mediante su uso por los actores y cambia porque otras formas culturales ganan prestigio y normalidad entre ellos. Es claro que existen muchos tipos de controles y sanciones negativas y positivas que operan sobre la repetición y sobre la innovación; pero es claro también que estos sectores y sanciones no están en las manos de una única institución diferenciada.

En los diversos países europeos se ha producido históricamente una separación entre la religión y la cultura, liberándose ésta primero de la tutela y luego de la conformación religiosa. La religión va perdiendo influencia en las diversas esferas sociales, interesándonos aquí principalmente la política y la cultural. Como el principal soporte de la cultura, en el sentido en que estoy utilizando el término, es su uso por los actores sociales, el proceso de secularización individual ha sido una dimensión central de este proceso de separación de esferas. Danièle Hervieu-Léger nos habla de un primer periodo de "descatolización" de la población francesa, por el cual Francia va pasando de ser un país de

\footnotetext{
${ }^{20}$ Les mutations des sciences sociales des religions et des laïcités. Autour des vingt ans du GSRL, Paris, 26-27 de noviembre de 2015.
} 
religión católica a ser un país de cultura católica, a través del continuado decrecimiento de la creencia y de la práctica religiosa. Y con ello, la capacidad de la Iglesia para controlar el comportamiento de los actores va decreciendo. Sin embargo, durante mucho tiempo la religión ha hecho un trabajo fuerte en la cultura, llegando a convertirse en una raíz fundamental de ésta. Pero después, un proceso al que esta autora llama de "exculturación" va borrando las raíces religiosas de la cultura (Hervieu-Léger, 2003).

En la España de después de la Guerra Civil, un proceso de descatolización comienza en los años sesenta del pasado siglo, años que son los del progresivo acceso de la población al consumo de masas; decae el interés por la religión y por la Iglesia; disminuyen la creencia y la práctica. España va pasando de ser un país de religión católica a ser un país de cultura católica. Este proceso es el dominante hasta los años noventa. Después empieza otro proceso con la entrada de nuevas generaciones, visible a través de los datos de encuesta, a comienzos del siglo actual; si la mayor parte de los jóvenes sigue definida como producto del proceso anterior, empieza a vislumbrarse que otra parte de esos jóvenes, particularmente notoria en zonas económicamente avanzadas de la sociedad española ${ }^{21}$, comienza a ser soporte de otro tipo de posición con respecto a la religión. Formas que no son ni religiosas ni anti-religiosas comienzan a ser muy amplias en estos sectores de la población. Jóvenes que no es que se alejen de la religión sino que la religión nunca ha formado parte de su conciencia; e, incluso, la raíz religiosa va desapareciendo de su cultura. En mis investigaciones he encontrado tres esferas de la vida en las que la religión - que había quedado como la raíz básica de las concepciones- ya en estos nuevos jóvenes va desapareciendo como determinante de maneras de pensar: el campo de la concepción de la familia, el matrimonio, la procreación; el campo de la representación de la propia muerte; el campo del trabajo y

\footnotetext{
${ }^{21}$ Ya en 2005, en las comunidades de Madrid, Cataluña y País Vasco, dos terceras partes de los jóvenes entre 15 y 24 años se definían como indiferentes, agnósticos o ateos (González Blasco, 2006). En el extremo, estos "nuevos ateos", presentan dos características sociales muy relevantes: por un lado, provienen familiarmente no de la de la vieja tradición de la izquierda anticlerical, sino más bien son herederos de un proceso de pérdida progresiva de interés en la religión por parte de sus padres; $y$, por el otro, su posición como ateos está acompañada por una actitud pluralista, tolerante; no se trata de un ateísmo militante sino más bien indiferente, muy lejano de las posiciones anticlericales propias del siglo XIX (Pérez-Agote, 2012: 324-340).
} 
la profesión. Es la exculturación. La cultura pierde sus raíces religiosas. (Pérez-Agote, 2012: cap. 4).

\section{LA HETEROGENEIZACIÓN CULTURAL Y RELIGIOSA DE NUESTRAS SOCIEDADES Y LAS TRANSFORMACIONES DE LAS RELACIONES DE LA RELIGIÓN CON LA CULTURA Y CON LA POLÍTICA}

Dentro del escenario de la teoría de la diferenciación social, podemos ver que se dan distintas maneras en las que religión y cultura pueden diferenciarse. Entre otras, está la manera en que la religión se libera de la cultura que la conformaba, como es el caso de los jóvenes de origen musulmán inmigrante educados en el medio educativo europeo que optan por volver a la religión de sus padres; otra manera está constituida por los procesos de secularización de la cultura en Estados Unidos (Herberg, 1955) o de descatolización y de exculturación en Francia (Hervieu-Léger, 2003) o en España (Pérez-Agote, 2012), procesos en los que es la cultura la que se libera de las amarras de la religión. En el caso de los jóvenes musulmanes europeos es la cultura islámica la que decae, y la religión, desprovista de su envoltura cultural, lleva a consecuencias variadas entre las que se encuentra la posibilidad de una radicalización religiosa; mientras que en el caso de la descatolización y la exculturación es la religión la que entra en crisis.

Las relaciones entre religión y cultura constituyen un lugar estratégico para entender las transformaciones de la religión en la sociedad contemporánea. Nuevos flujos migratorios conducen a la heterogeneización religiosa de nuestras sociedades. En general se puede decir que en las sociedades de donde provienen estos flujos no se ha producido, al menos con la misma intensidad que en Europa, un proceso de diferenciación de la religión en relación a otras esferas, como la cultura y la política. En muchas ocasiones, en los países europeos, esta diferencia en el nivel de diferenciación de la religión entre la población autóctona y la de origen inmigrante ha sido y es una fuente de conflictos sociales profundos. Podemos recordar la cuestión del velo islámico en Francia y el llamado Rapport Stasi de 2003. En este informe se recomienda la prohibición en la escuela de "vestimentas y signos (tenues et signes) religiosos" (Stasi, 2003: 68). La única especificación que el informe hace sobre la significación del velo es que puede revestir "diferentes significaciones. Puede ser una elección personal o al contrario una imposición (contrainte)..." (Ibid.: 57). Es evidente que la 
Comisión Stasi estableció sus conclusiones desde una única perspectiva, la de la población francesa autóctona: el velo es un símbolo religioso. Desde una perspectiva cultural diferente, en la que no se da la clara separación entre cultura y religión y en la que no encontramos una religión diferenciada, el velo es un símbolo religioso-cultural-familiar, y para determinadas ocasiones podemos añadir que también es político. Las políticas derivadas de este informe, y, por tanto, el informe mismo se convirtieron en factores de re-significación política del velo para la población de origen inmigrante. La Comisión Stasi adoptó una perspectiva etnocéntrica, basada en la creencia de que Francia era una sociedad culturalmente homogénea; y en 2003 ya claramente no lo era.

En otro lugar ya se ha replanteado el principio de laicidad directamente desde la política, separándolo de las formas de interpretación y aplicación. Gérard Bouchard y Charles Taylor (2008), en un informe elaborado a propuesta del Primer Ministro de Québec, han promovido una nueva idea: la de "laicidad abierta". Para estos autores, son cuatro los principios que definen el laicismo; dos de los cuales son fundamentales para ellos: la igualdad moral de las personas y la libertad de conciencia y de religión. Los otros dos se han convertido en interpretables: el principio de la separación de Iglesia y Estado, y la neutralidad del Estado en relación con las religiones y las creencias seculares profundas (Ibid.: 135-136). Con ello se abre una importante posibilidad de medidas pragmáticas que no implicarian contradicción insalvable con la dimensión "fundamental" de la laicidad.

La diferencia crucial entre el informe Stasi y el de Bouchard y Taylor, deriva de la idea de sociedad que presupone cada uno de ellos. En el primero, se está pensando en una ciudadanía uniforme, culturalmente homogeneizada, y se conserva la idea de laicidad propia de la época de separación entre el Estado francés y la Iglesia católica francesa, proceso que culminaría con la Ley de 1905 . Y se aplica el esquema de separación a la nueva realidad social, con referencia a confesiones religiosas cuyo soporte social son minorías sociales de origen inmigrante que no tienen la posibilidad de enfrentarse con fuerza al Estado y que constituyen a su religión y a sus formas de culto en mecanismos de solidaridad e identidad. En cambio, el informe de los autores canadienses, nace de la necesidad de tener en cuenta la existencia de estas nuevas poblaciones $y$ de proteger hasta un cierto punto estas instituciones sociales 
religiosas, como mecanismo de integración social de estas poblaciones minorizadas.

Las sociedades europeas han sido sociedades relativamente ${ }^{22}$ homogéneas desde el punto de vista religioso. Pero ahora un sector de su población, de origen inmigrante ( $y$ en una parte importante ya nacional desde el punto de vista jurídico), profesa confesiones religiosas diferentes a la históricamente dominantes. La religión, para este sector, tiene un papel social importante en la integración social de la comunidad, al que ya me he referido; $y$, además, estos grupos religiosos necesitan claramente del apoyo, económico y político, para el desarrollo de su actividad religiosa. Tanto más cuanto que el mecanismo fundamental de integración social que es el mercado de trabajo se está alejando progresivamente del control del Estado por la globalización de la economía. La cuestión de la separación Iglesia y Estado comienza a replantearse, aunque en Europa tímidamente por el momento ${ }^{23}$.

Los Estados europeos no pueden enfrentarse a las confesiones religiosas no dominantes de la misma manera que se enfrentan a la confesión históricamente dominante. En España, el proceso de secularización subjetiva es muy tardío - en relación a Francia, por ejemplo- y muy rápido; el proceso de separación entre la Iglesia católica y el Estado entró con la transición democrática (1975-1978) en un proceso difícil de separación. Sin estar aún claramente establecida, un fuerte contingente de inmigración comienza con el siglo actual ${ }^{24}$ y pone de relieve una nueva diversidad religiosa que necesita progresivamente de la religión como mecanismo de integración e identidad comunitarias, sobre todo

\footnotetext{
${ }^{22}$ Relativamente, porque siempre existen otras formas no religiosas y otras confesiones distintas de la dominante.

${ }^{23}$ Pero la diferenciación entre religión y política tiene abierta, además, otra vía de crisis. Las Iglesias cristianas europeas occidentales y muy en particular la Iglesia católica, han reaccionado con una cierta virulencia contra ciertas leyes que se han venido aprobando en los parlamentos europeos a partir de los años 1970. Leyes relativas a temas éticos e intimos: la familia, el matrimonio, la reproducción, la vida. En una reciente investigación pudimos comparar las repuestas de la Iglesia católica a este tipo de leyes en cinco países de tradición histórica católica: Bélgica, España, Francia, Italia y Portugal (Dobbelaere y Pérez-Agote, 2015). En los cinco países hemos encontrado un cierto rearme político de la Iglesia católica. Podemos recordar, como caso más flagrante, el de la virulenta reacción de la Iglesia francesa contra la ley que permite el matrimonio entre homosexuales, algo que no era predecible dada la histórica aceptación por parte de esa Iglesia de la ley de 1905, que consagraba la separación absoluta entre ambas instituciones (Béraud y Portier, 2015).

${ }^{24}$ Se pasa de menos de un $2 \%$ de población extranjera a más de un $12 \%$ en tan solo una decena de años.
} 
con la nueva crisis económica que comienza en el entorno de 2008. De manera que sin una tradición sólida de separación Iglesia-Estado, conservando la Iglesia católica gran fuerza política, y con la llegada de fuertes contingentes de población no católica, el Estado, a través de sus cambiantes gobiernos ha puesto en práctica un modelo pragmático de relaciones con las nuevas confesiones religiosas. Se ha avanzado en su reconocimiento jurídico y en la colaboración con ellas, sobre todo a través del Ministerio de Justicia y de la Fundación Pluralismo y Convivencia $^{25}$, generada a partir de ese organismo, cuya labor ha sido muy eficiente a pesar de sus recursos muy escasos ${ }^{26}$.

En abril de 2008 el CIS desarrolló el trabajo de campo de su Estudio nº 2759, llevado a cabo en centros de culto, de confesiones no católicas, inscritos en el Ministerio de Justicia, mediante un cuestionario elaborado por Jose Santiago y por mí. Del análisis de los datos obtenidos sacamos resultados relevantes sobre las funciones sociales de los centros de culto religioso de las nuevas confesiones religiosas:

"Al estudiar las entidades religiosas (...) nos hemos encontrado con una realidad multifuncional muy rica, desde el punto de vista de las actividades que se llevan a cabo dentro de ellas. Como es lógico, las actividades religiosas colectivas son las más comunes, seguidas muy de cerca por la lectura de textos sagrados y por las charlas. Vienen después, en importancia, el consejo moral, la oración individual, el encuentro y la confraternización, los cursos de formación y las actividades festivas $y$, por último, la ayuda y solidaridad en temas pragmáticos prototípicos de la situación de los inmigrantes (vivienda, trabajo, 'papeles', etc.). (Pérez-Agote y Santiago, 2009: 93).

Y, ya al final del trabajo, poníamos de relieve:

"la contribución de estas asociaciones a la formación de estructuras de plausibilidad para el mantenimiento de una identidad originaria con una valoración o estima positiva; un lugar donde 'los otros', los diferentes dentro de la sociedad española pueden sentirse 'normales'; claro está que estos centros no son el único mecanismo de re-producción de la identidad original, pero sí uno muy importante; y constituyen, sin duda ninguna, un medio poderoso de integración social. La integración de una persona socialmente minorizada pasa, al

${ }^{25}$ Consultable en: www.pluralismoyconvivencia.es.

${ }^{26}$ Sobre todo a partir del Observatorio del Pluralismo Religioso en España: www.observatorioreligion.es. 
menos en parte, por su participación en mecanismos de integración colectiva, como estas entidades religiosas" (Ibid.: 151).

Hemos visto cómo el fuerte incremento de la pluralidad religiosa y la subsiguiente minorización social en una época de crisis económica y de crisis de la soberanía del Estado - es decir, de la merma de la capacidad de éste para resolver los problemas sociales internos- las religiones minorizadas constituyen un recurso - muchas veces el único posiblede unión, de construcción de comunidad, identidad colectiva. Y, en cierta medida, es la identidad colectiva más amplia, la que constituye, sobre ese territorio, el límite.

Por último, quiero poner de relieve otro aspecto de la relación entre la religión y la identidad en el que no podemos entrar, pues constituye una cuestión muy compleja y muy escasamente abordada por la investigación social. Es el aspecto relativo al tercer nivel de autoconcepto del yo, el referido al que diferencia a cada individuo de todos los otros. El proceso de secularización subjetiva de nuestras sociedades, que en parte implica una fuerte privatización de la religión, nos lleva a preguntarnos si en muchos casos más allá de la privacidad, la religión se sitúa en la intimidad, con lo que el sentimiento y la experiencia religiosa no busca la intersubjetividad, sino que se queda en pura espiritualidad o religiosidad personal, sin institución social que la controle. Lo religioso puede así ser lo más íntimo del yo, inaccesible incluso a quienes forman parte del núcleo más privado de la persona.

\section{Bibliografía}

Adogame, A. (Ed.). (2014). The Public Face of African New Religious Movements. Imagining the Religious «Other». Farnham: Ashgate.

Béraud, C., \& Portier, P. (2015). Métamorphoses catholiques. Paris: Fondation de la Maison des Sciences de l'Homme.

Berger, P. L. (1967). Religious Institutions. In N. J. Smelser (Ed.). Sociology: an introduction (pp. 329-378). New York: Wiley.

Boucenna, B. (2016). Ces enfants d'immigrés qui réussissent. Parcours, devenir socioprofessionnel et stratégies familiales. Paris: L'Harmattan.

Bouchard, G., \& Taylor, C. (2008). Fonder l'avenir: le temps de la conciliation: rapport abrégé. Commission de consultation sur les pratiques d'accommodement reliées aux différences culturelles. 
Rapport final. Québec: Gouvernement du Québec. Disponible en: http://collections.banq.9c.ca/ark:/52327/bs66285. Última consulta: 25/07/2016.

Dobbelaere, K., \& Pérez-Agote, A. (Eds.) (2015). The Intimate: New Conflicts between Religion and Polity. Laws about Life, Death and the Family in so-called Catholic Countries. Leuven: Leuven University Press.

Durkheim, E. (1967). Sociologie et philosophie. Paris: Presses Universitaires de France.

Durkheim, E. (2007). Les formes élémentaires de la vie religieuse. Paris: Presses Universitaires de France.

González Blasco, P. (Coord.). (2006). Jóvenes españoles 2005. Madrid: Fundación Santa María-Ediciones SM.

Greenfeld, L. (1992). Nationalism. Five roads to Modernity. CambridgeLondon: Harvard University Press.

Herberg, W. (1955). Protestant-Catholic-Jew: An Essay in American Religious Sociology. New York: Doubleday \& Company.

Hervieu-Léger, D., \& Willaime, J.-P. (2001). Sociologies et religion. Approches classiques. Paris: Presses Universitaires de France.

Hervieu-Léger, D. (2003). Catholicisme, la fin d'un monde. Paris: Bayard.

Kepel, G. (2015). Quel avenir pour l'islam? Rencontre avec Gilles Kepel. Sciences Humaines, 4(6), 96-98.

Khosrokhavar, F. (1994). Marginalisation de la jeunesse, marginalisation des élites. In A. Gresh (Dir.), Un péril islamiste? (pp. 129-147). Paris: Editions Complexe.

Kivisto, P. (2014). Religion and Immigration. Migrant Faiths in North America and Western Europe. Cambridge: Polity Press.

Kohn, H. (1949). Historia del nacionalismo. México: Fondo de Cultura Económica.

Lapeyronnie, D. (1987). Assimilation, mobilisation et action collective chez les jeunes de la seconde génération de l'immigration maghrébine. Revue Française de Sociologie, 28(2), 287-318.

Merton, R. K. (1980). Teoría y Estructura Sociales. México: Fondo de Cultura Económica.

Nisbet, R. A. (1973). The Quest for Community. New York: Oxford University Press. 
Pérez-Agote, A. (1995). Un modelo fenomenológico-genético para el análisis de la dimensión política de la identidad colectiva en el Estado de las Autonomías. In J. Beramendi, R. Máiz \& X. M. Núñez (Eds.), Nationalism in Europe. Past and Present (307-323). Santiago de Compostela: Universidad de Santiago.

Pérez-Agote, A. (2006). The Social Roots of Basque Nationalism. Reno: The University of Nevada Press. Versión española: (2008). Las raíces sociales del nacionalismo vasco. Madrid: Centro de Investigaciones Sociológicas.

Pérez-Agote, A. (2012). Cambio religioso en España. Los avatares de la secularización. Madrid: Centro de Investigaciones Sociológicas.

Pérez-Agote, A. (2014). The notion of secularization: Drawing the boundaries of its contemporary scientific validity. Current Sociology, 62(6), 886-904.

Pérez-Agote, A., \& Santiago, J. (2009). La nueva pluralidad religiosa. Madrid: Ministerio de Justicia.

Ritzer, G. (1996). The McDonaldization thesis: Is expansion inevitable?. International Sociology, 11(3), 291-308.

Roy, O. (2015). Le djihadisme est une révolte générationnelle et nihiliste. Le Monde, 24 noviembre.

Roy, O. (2005). La Laïcité face à l'islam. Paris: Stock.

Smelser, N. J. (Ed.). (1967). Sociology: an introduction. New York: Wiley.

Stasi, B. (2003). Rapport au Président de la République. Commission de reflexion sur l'application du principe de laïcité dans la République, 11 de diciembre. Disponible en: http://www.ladocumentationfrancaise.fr/var/storage/rapportspublics/034000725/0000.pdf. Última consulta: 25/07/2016.

Tajfel, H. (1984). Grupos humanos y categorías sociales. Barcelona: Herder.

Thomas, W. I. (1923). The Unadjusted Girl. Boston: Little Brown.

Thomas, W. I., \& Znaniecki, F. (1958). Polish Peasant in Europe and America. New York: Dover.

Tietze, N. (2002). Jeunes musulmans de France et d'Allemagne. Les constructions subjectives de l'identité. Paris: L'Harmattan.

Tilly, C. (1990). Coercion, Capital, and European States, AD 990-1990. Cambridge, Mass.-Oxford: Basil Blackwell.

Turner, J. C. (1990). Redescubrir el grupo social. Madrid: Morata. 
Wieviorka, M. (1998). Le multiculturalisme est-il la réponse? Cahiers Internationaux de sociologie, 105, 233-260. 